\title{
Pengaruh Quality Of Work Life (Qwl) dan Beban Kerja Terhadap Kepuasan Kerja Pegawai Pada Kantor Kesyahbandaran dan Otoritas Pelabuhan Kelas di Kijang
}

\author{
Intan Novita Sari, Myrna Sofia, Nurhasanah
}

Fakultas Ekonomi Universitas Maritim Raja Ali Haji, Tanjungpinang, Kepulauan Riau, Indonesia

\begin{abstract}
ABSTRAK : Penelitian ini bertujuan untuk mengetahui dan menganalisis apakah terdapat pengaruh quality of work life dan beban kerja terhadap kepuasan kerja pegawai pada Kantor X. Penelitian ini dikategorikan sebagai penelitian kuantitatif dengan instrumen berupa kuesioner. Populasi dalam penelitian ini adalah seluruh pegawai Kantor X sebanyak 41 orang. Teknik pengambilan sampel dengan cara teknik sampling jenuh atau sensus. Sampel dalam penelitian ini adalah dengan mengambil populasi atau sebanyak 41 sampel. Data yang digunakan dalam penelitian ini adalah data primer yang diperoleh melalui Kuesioner. Uji validitas instrumen menggunakan rumus Correclation Bivariate, sedangkan uji reliabilitas menggunakan Cronbach Alpha. Alat ukur terbukti valid dan reliabel untuk instrumen penelitian. Analisis regresi berganda digunakan untuk uji hipotesis penelitian ini. Berdasarkan hasil penelitian ini diketahui bahwa hasil uji regresi linier berganda adalah $\mathrm{Y}=2,826+0,16 \mathrm{X} 1+$ 1,082 X2, dimana Quality Of Work Life (X1), Beban Kerja (X2), dan Kepuasan Kerja(Y). Kemudian hasil uji $\mathrm{T}$ variabelQuality Of Work Lifetidak berpengaruh signifikan terhadap kepuasan kerja pegawai $(1,488<$ 1,68288). Beban kerja berpengaruh signifikan yaitu $(22,009>1,6828$. Uji F secara bersama-sama terdapat pengaruh signifikan terhadap kepuasan kerja pegawai ( 247,626 > 2,85 ). Hasil uji R square memberikan nilai sebesar 0,925 yang artinya 92,5\% variabel kepuasan kerja pegawai dapat dijelaskan melalui kedua variabel independen, Sedangkan sisanya sebesar 7,5\% dipengaruhi atau dijelaskan oleh faktor-faktor lain yang tidak dimasukkan dalam penelitian ini.
\end{abstract}

Kata Kunci: Quality Of Work Life, Beban kerja, dan Kepuasan kerja pegawai.

\begin{abstract}
ABSTRAK : This study aims to determine and analyze whether there is influence of, quality of work life and workload to against employee job satisfaciton at Office $X$. This research is categorized as quantitative research with questionnaire instrument. Population in this research is all employees of Office X counted 41 people. Sampling technique by means of saturated sampling technique or census. The sample in this study is to take the population or as many as 41 samples. The data used in this study is the primary data obtained through Questionnaire. Instrument validity test using Correclation Bivariate formula, while reliability test using Cronbach Alpha. Measurers proved to be valid and reliable for research instruments. Multiple regression analysis is used to test the hypothesis of this research.Based on the results of this study it is known that the results of multiple linear regression test is $Y=2,826+0,16 X 1+1,082 X 2$ where, quality of work life $(X 1)$, workload (X2 and job satisfaction $(Y)$. Then $T$ test results of variable quality of work life does not significantly affect employee job satisfaction (1,488 < 1,68288). Workload has a significant effect that is $(22,009>1,6828$. Test $F$ together there is a significant influence on employee job satisfaction $(247,626>2,85 . R$ square test results give a value of 0,925 which mean $92,5 \%$ employee satisfaction variable can be explained through two independent variables, while the rest of 7,5\% influenced or explained by other factors not included in this study.
\end{abstract}

Keywords: : Quality Of Work Life, workload and job satisfaction of employess.

Email Address : intan.ns@gmail.com 


\section{Pendahuluan}

Sumber daya manusia merupakan penggerak utama suatu perusahaan/instansi.Pencapaian tujuan instansi akan terwujud apabila ditunjang oleh sumber daya manusia yang berkualitas. Pegawai sebagai sumber daya manusia yang dimiliki instansi adalah manusia yang mempunyai sifat kemanusiaan, perasaan dan kebutuhan yang beraneka ragam.

Salah satu masalah pokok dalam manajemen sumber daya manusia adalah bagaimana mencari cara yang terbaik untuk mencapai kepuasan pegawai. Kepuasan kerja pegawai merupakan salah satu aspek penting yang perlu diperhatikan dalam usaha peningkatan kualitas sumber daya manusia suatu instansi, apabila kepuasan kerja pegawai terpenuhi, mereka akan cenderung memiliki motivasi untuk bekerja, sebaliknya ketidakpuasan akan mengakibatkan tingginya tingkat keluar masuk pegawai, ketidakhadiran, pemogokan, dan tindakan-tindakan negatif lainnya yang dapat merugikan instansi. Penelitian terhadap kepuasan pegawai dapat mengetahui hal-hal yang perlu diperhatikan untuk memperoleh kondisi kerja yang mendukung kepuasan pegawai sehingga dapat tercipta pegawai yang berkualitas, selain itu dengan mengetahui tingkat mengetahui QWLdiharapkan dapat memberikan gambaran mengenai tingkat kepuasan pegawai. Kepuasan merupakan hal yang bersifat individual, setiap individu memiliki tingkat kepuasan yang berbeda-beda, sehingga pengukurannya pun sangat bervariasi. Selain itu tolak ukur yang mutlak dalam mengukur tingkat kepuasan tidak ada (Hasibuan, 2003). Oleh karena itu, diperlukan suatu cara dalam mengukur tingkat kepuasan pegawai suatu instansi. Salah satu cara dalam mengukur tingkat kepuasan pegawai adalah dengan mengetahui perasaan pegawai terhadap aspek-aspek pekerjaannya.

Oleh karena itu pihak manajemen perlu mengetahui apa saja yang dapat mempengaruhi kepuasan pegawai. Dengan mengetahui Quality Of Work Life (QWL), diharapkan pihak manajemen memperoleh jawaban mengenai apa saja yang sekiranya mempengaruhi kepuasan kerja pegawai sehingga instansi dapat meningkatkan kepuasan para pegawainya yang pada akhirnya dapat membantu instansi untuk mencapai tujuan-tujuannya. Hal ini didukung dengan hasil penelitian yang dilakukan oleh (Prasetyawati \& Kusnudin, 2015) menyatakan Quality Of Work Lifeberpengaruh signifikan terhadap kepuasan kerja dan jurnal internasional mengenai QWL oleh ( Khera, 2015) menyatakan bahwa QWL berpengaruh positif dan signifikan terhadap kepuasan kerja.

\section{Kajian Pustaka \\ Kepuasan Kerja}

Kepuasan kerja bisa diartikan sebagai sikapemosional pegawai yang mencintai dan menyenangi pekerjaannya (Hasibuan, 2003). Kepuasan atau ketidakpuasan pegawai tergantung pada perbedaan antara apa yang diharapkan. Apabila yang didapat karyawan lebih rendah dari pada yang diharapkan akan menyebabkan pegawai tidak puas. kepuasan kerja adalah suatu perasaan yang menyenangkan atau tidak menyenangkan diri pegawai yangberhubungan dengan pekerjaannya maupun dengan kondisi dirinya (Purbaningrat Yo \& Ketut Surya dalam Handoko, 2001:1930).

\section{Quality of Work Life (QWL)}

Quality Of Work Life dapat didefinisikan sebagai persepsi pegawai tentang kesejahteraan mental dan fisiknya ketika bekerja. ada dua pandangan mengenai maksud dari kualitas kehidupan kerja.

QWL merupakan suatu proses dimana organisasi merespon terhadap kebutuhan pegawai dengan mengembangkan mekanisme dengan melibatkan mereka dalam mendesain kehidupan kerja dengan definisi lain, merupakan kondisi kerja yang menyenangkan yang mendukung dan meningkatkan kepuasan pegawai dengan menyediakan reward, keamanan kerja serta kesempatan untuk 
berkembang (Rokhman dalam Pathak, 2012). QWL merupakan keadaan dimana para pegawai dapat memenuhi kebutuhan bekerja dalam organisasi, dan kemudian untuk melakukan hal itu bergantung pada apakah terdapat adanya :

1. Perlakuan yang fair/ adil dan suportif terhadap pegawai.

2. Kompensasi yang cukup dan fair

3. Lingkungan yang aman dan sehat

4. Kesempatan bagi tiap karyawan untuk menggunakan kemampuan secara penuh.

5. Komunikasi terbuka dan saling mempercayai di antara semua karyawan

6. Kesempatan bagi semua karyawan untuk berperan secara aktif dalam pengambilan keputusan-keputusan.

\section{Beban Kerja}

Beban kerja adalah suatuperbedaan antara kapasitas atau kemampuan pekerja dengan tuntutan pekerjaan yang harus dihadapi (Astianto dalam Meshkati, 2011). Positif negatifnya beban kerja merupakan masalah persepsi. Persepsi didefinisikan sebagai suatu proses dimana individu mengorganisasikan dan menafsirkan kesan indera mereka agar memberi makna kepada lingkungan mereka. Persepsi terhadap beban kerja berkaitan dengan faktor atribut peran dan pekerjaan.

\section{Kerangka Pemikiran}

Kerangka penelitian ini menunjukkan pengaruh variabel independen terhadap variabel dependen. Variabel independen dalam penelitian ini adalah Quality Of Work Life(X1) dan beban kerja (X2), sedangkan variabel dependennya adalah kepuasan kerja (Y) yaitu sebagai berikut :

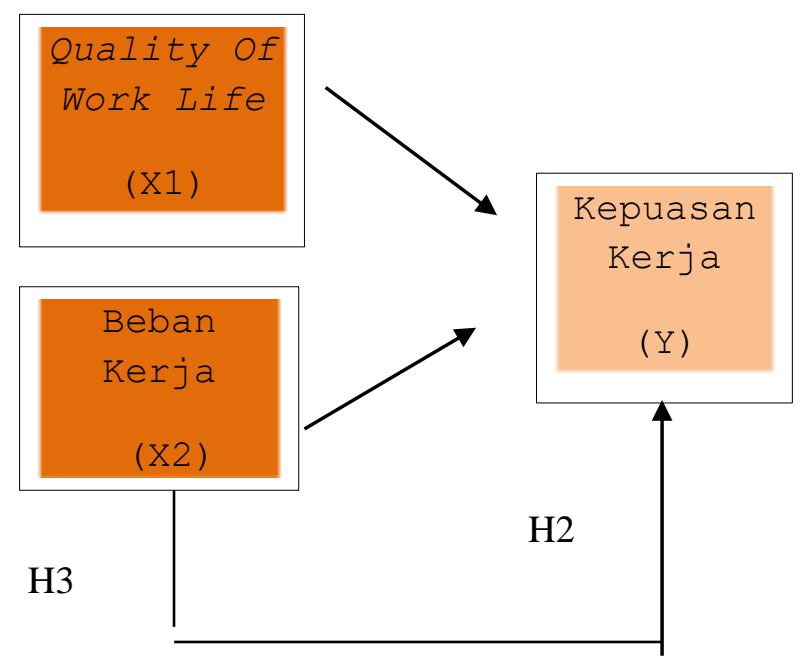

Gambar 2.1: Kerangka Pemikiran

Sumber: Alamsyah (2015), Arifin (2012,

Prasetyawati \& Kusnudin (2015).

\section{Pengembangan Hipotesis}

Pengaruh Quality Of Work Life Terhadap Kepuasan Kerja Pegawai.

Quality Of Work Life (QWL) mengacu pada keadaan yang menyenangkan atau tidak menyenangkannya lingkungan pekerjaan bagi seseoorang. Sumarsono (2004) mendefinisikan QWL sebagai salah satu pendekatan sistem manajemen untuk mengkoordinasikan dan menghubungkan potensi SDM dalam organisasi, sebagai suatu upaya pimpinan untuk memenuhi kebutuhan anggota maupun organisasi secara simultan dan terus menerus. Dari pembahasan di atas maka hipotesis 1 penelitian dalam bentuk alternatif berbunyi :

\section{H1 : Quality Of Work Life (QWL) signifikan terhadap kepuasan kerja pegawai.}

\section{Pengaruh Beban Kerja Terhadap Kepuasan Kerja Pegawai}

Beban kerja artinya setiap karyawan melaksanakan tugas pekerjaan yang dipercayakan untuk dikerjakan dan dipertanggungjawabkan oleh satuan organisasi atau seorang karyawan tertentu sesuai dengan kemampuan dan kesanggupan sehingga efektivitas kerja akan berhasil dengan baik. Cole, et al(2004) menyatakan tekanan beban kerja yang berlebihan dapat berdampak pada 
penurunan kepuasan kerja karyawan. Adanya penerapan beban kerja membuat karyawan dituntut untuk mengeluarkan seluruh potensi yang dimiliki. Beban kerja yang dilakukan oleh supervisor menjadi sangat penting, karena berkaitan dengan kepuasan karyawan dalam bekerja. Dalam PenelitianDhani (2010) mengatakan bahwa beban kerja memiliki pengaruh signifikan terhadap kepuasan kerja.

\section{H2 : Beban Kerja berpengaruh signifkan terhadap kepuasan kerja pegawai}

\section{Pengaruh Quality Of Work Life dan Beban Kerja Terhadap Kepuasan Kerja Pegawai}

Quality Of Work Life dan Beban Kerja berkaitan dalam peningkatan kepuasan kerja pegawai, sehingga untuk memenuhi kepuasan kerja pegawainya instansi perlu memperhatikan kedua hal tersebut. Apabila quality of work life meningkat maka kepuasan kerja juga akan mengalami peningkatan. Hal ini didukung oleh penelitian Nurbi (2013), mengatakan bahwa QWL berpengaruh signifikan terhadap kepuasan kerja karyawan. Berikutnya jika beban kerja meningkat maka kepuasan kerja akan menurun. Variabel beban kerja dan hubungannya dengan kepuasan kerja juga diteliti olehDhani (2010) yang mengatakan bahwa beban kerja memiliki pengaruh dan signifikan terhadap kepuasan kerja.

\section{H3 :Quality Of Work Life dan Beban Kerja berpengaruh signifikan terhadap kepuasan kerja.}

\section{Metodologi Penelitian}

Penelitian ini termasuk dalam penelitian asosiatif kausal dengan menggunakan pendekatan kuantitatif. Penelitian asosiatif kausal menurut Nurfiani dalam Nursanti, (2014) adalah penelitian yang bertujuan mengetahui pengaruh antara dua variabel atau lebih. Dalam penelitian ini menggunakan metode kuntitatif karena data yang digunakan akan menganalisis hubungan antar variabel yang dinyatakan dengan angka. Penelitian ini menghubungkan pengaruh Quality Of Work Life dan beban kerja terhadap kepuasan kerja pegawai.

\section{Operasionalisasi Variabel Penelitian Variabel Terikat (Dependen)}

Variabel dependen merupakan "variabel yang dipengaruhi oleh variabel independen, oleh karena itu, variabel dependen bergantung pada variabel independen". (Irawati dalam Silalahi 2004: 133). Dalam penelitian ini variabel dependen nya adalah kepuasan kerja.

\section{Variabel Bebas (Independen)}

Variabel independen merupakan "variabel yang dipengaruhi oleh variabel independen. Oleh karena itu, variabel dependen bergantung pada variabel independen. Dalam penelitian ini, variabel bebasnya adalah:

a) Variabel Quality Of The Work (X1)

b) Variabel Beban Kerja (X2).

\section{Metode Analisis \\ Uji Kualitas Data \\ Uji Validitas}

Untuk mengukur validitas dapat dilakukan dengan melakukan korelasi antar skor butir pertanyaan dengan total skor konstruk atau variabel. Sedangkan untuk mengetahui skor masing - masing item pertanyaan valid atau tidak, maka ditetapkan kriteria statistik sebagai berikut:

a. Jika $\mathrm{r}$ hitung $>\mathrm{r}$ tabel dan bernilai positif, maka variabel tersebut valid

b. Jika $\mathrm{r}$ hitung $<\mathrm{r}$ tabel, maka variabel tersebut tidak valid.

c. Jika $\mathrm{r}$ hitung $>\mathrm{r}$ tabel tetapi bertanda negatif, maka $\mathrm{H} 0$ akan tetap ditolak dan H1 diterima.

Sebelum diadakan penelitian lebih lanjut, setiap butir soal instrumen harus memenuhi syarat validitas dengan skor total menggunakan Pearson's Product Moment. Dari perhitungan tersebut menghasilkan butir 
yang valid dan yang tidak valid Paiahantaraf signifikansi $\alpha=0,05$ dengan $\mathrm{dk}=\mathrm{n}-1$

\section{Uji Reliabilitas}

Adapun metode yang digunakan dalam penelitian ini adalah metode Alpha yaitu metode untuk mencari reabilitas internal yaitu menganalisis reabilitas alat ukur dari satu kali pengukuran. Uji reliabilitas dapat dilakukan dengan menggunakan bantuan program Microsoft excel yang akan memberikan fasilitas untuk mengukur reliabilitas dengan uji statistik Cronbach Alpha $(\alpha)$. Suatu konstruk atau variabel dikatakan reliabel jika memberikan nilai Cronbanch Alpha > 0,60 ( Jhonatans, 2012 )

\section{Uji Asumsi Klasik}

\section{Uji Multikolineritas}

Uji Multikolineritas ini bertujuan untuk menguji apakah dalam model regresi ditemukan adanya korelasi antar variabel bebas. Apabila Multikolineritas terjadi maka koefisien dari pada variabel $\mathrm{X}$ tidak adapat ditentukan (indeterminanci) dan standar erornya tak terhingga (infinitive). (Suparno dalam suripto, 2013).

\section{Uji Normalitas}

Uji normalitas bertujuan untuk menguji apakah dalam sebuah model regresi, variabel dependen dan variabel independen mempunyai distribusi normal atau tidak. Data yang normal akan memperkecil kemungkinan terjadinya bias.

Uji normalitas dengan melihat penyebaran data (titik) pada sumbu diagonal dari grafik (Santoso dalam Suripto, 2013).

\section{Analisis Regresi Linier Berganda}

Analisis linier berganda dipakai untuk mengetahu besarnya pengaruh variabel bebas (Quality Of Work Life dan beban kerja) terhadap variabel terikat (kepuasan kerja)

Dengan menggunakan rumus (Santoso, 2013), sebagai berikut:

$$
\mathrm{Y}=\beta \mathrm{o}+\beta_{1} \mathrm{X}_{1}+\beta_{2} \mathrm{X}_{2}++\mathrm{e}
$$

$\beta_{1,=}$ koefisien masing-masing variabel bebas

$\mathrm{Y} \quad=$ Kepuasan Kerja Pegawai

$\mathrm{X} 1=$ Quality of Work Life

$\mathrm{X} 2=$ Beban Kerja

Bo $=$ Konstan

e $=$ error

\section{Uji T (Parsial)}

Uji t digunakan untuk mengetahui ada tidaknya hubungan atau pengaruh yang berarti (signifikan) antara variabel independen (Quality Of Work Life dan beban kerja) secara parsial terhadap variabel dependen (kepuasan kerja). (Sunyoto, 2011).

\section{Uji F (Simultan)}

Uji $\mathrm{F}$ adalah alat untuk menguji kebenaran pengaruh variabel independen $(\mathrm{X})$ terhadap variabel dependen (Y) secara bersama-sama sehingga dapat dibuktikan bahwa pengaruh yang didapat bukan satu kebetulan belaka (Sugiyono dalam Rofi, 2012).

Pengujian dilakukan dengan membandingkan $\mathrm{F}$ hitung dan $\mathrm{F}$ table,kriteria pengujian $\mathrm{F}$ sebagai berikut :

1. Apabila $\mathrm{F}$ hitung $>\mathrm{F}$ table maka Ho akan ditolak dan Ha akan diterima, dapat diartikan bahwa variabel independen mempunyai pengaruh signifikan terhadap variable dependen secara simultan.

2. Apabila $F$ hitung $\leq \mathrm{F}$ table maka Ho akan diterima Ha ditolak dapat diartikan bahwa variabel independen tidak mempunyai pengaruh yang signifikan terhadap variabel dependen secara simultan.

\section{Koefisien Determinasi $\left(\mathbf{R}^{\mathbf{2}}\right)$}

Koefisien determinasi $\left(\mathrm{R}^{2}\right)$ adalah koefisien yang berfungsi untuk menjelaskan kemampuan independen untuk menjelaskan variasi perubahan naik turunnya variabel dependen. Nilai $\mathrm{R}^{2}$ mempunyai interval antara 0 sampai $1(0 \leq \mathrm{R} \leq 1)$. Semakin besar $\mathrm{R}$ (mendekati 1), semakin baik hasil untuk model 
regresi tersebut dan semakin mendekati 0 , maka variabel independen tidak dapat menjelaskan variabel dependen (Parmin, 2014).

\section{Pembahasan dan Hasil}

\section{Pengaruh Quality Of Work Life Terhadap Kepuasan Kerja Pegawai}

Hasil uji hipotesis pertama yang ditunjukkan pada tabel 4.15 nilai thitung 1,488. Ini berarti nilai sig lebih besar dari taraf signifikansi $0,145(<0,05)$. Dan berdasarkan perbandingan $\mathrm{t}$ hitung dengan $\mathrm{t}$ tabel $(\mathrm{t}$ tabel $\alpha=0,05)$. Didapat $t$ hitung 1,488 lebih besar dari $\mathrm{t}$ tabel $1,68288(1,488<1,68288)$. Maka dalam hal ini Ha ditolak dan $\mathrm{HO}$ diterima sehingga quality of work life tidak berpengaruh secara parsial terhadap kepuasan kerja.

\section{Pengaruh Beban Kerja Terhadap Kepuasan Kerja Pegawai}

Hasil uji hipotesis kedua yang ditunjukkan pada tabel 4.15nilai $\mathrm{t}$ hitung 22,009 . Ini berarti nilai sig lebih kecil dari taraf signifikansi $0,00 \quad(<0,05)$. Dan berdasarkan perbandingan $\mathrm{t}$ hitung dengan $\mathrm{t}$ tabel $(\mathrm{t}$ tabel $\alpha=0,05)$. Didapat t hitung 22,009 lebih kecil dari t tabel 1,68288 (22,009>1,68288). Maka dalam hal ini $\mathrm{Ha}$ ditolak dan $\mathrm{H} 0$ diterima sehingga beban kerja berpengaruh secara parsial terhadap kepuasan kerja.

Nilai koefisien regresi variabel beban kerja adalah 0,1082 . Nilai beban kerja yang menunjukkan adanya hubungan yang searah antara variabel kepuasan kerja dengan beban kerja yang artinya jika beban kerja mengalami peningkatan 1 (satu), maka kepuasan akan mengalami peningkatan sebesar 0,1082 dengan asumsi bahwa variabel bebas lainnya tetap.

\section{Pengaruh Quality Of Work Lifedan Beban Kerja Terhadap Kepuasan Kerja Pegawai}

Dari hasil koefisien determinasi parsial memperlihatkan, kontribusi variabel quality of work lifedalam mempengaruhi kepuasan kerja pegawai sebesardisimpulkan bahwa nilai signifikansi 0,000 dan nilai $F_{\text {hitung }} 247,626$ ini berarti nilai sig lebih kecil dari $0,05(0,000<$ 0,05). Dan berdasarkan perbandingan $F_{\text {hitung }}$ dengan $\mathrm{F}_{\text {tabel }} \quad\left(\mathrm{F}_{\text {tabel }} \alpha=0,05\right)$ didapat $\mathrm{F}_{\text {hitung }}$ 247,626 lebih besar dari $F_{\text {tabel }}$ yaitu 2,85 $(247,626>2,85)$. Maka dalam hal ini $\mathrm{H}_{\mathrm{a}}$ diterima dan $\mathrm{H}_{\mathrm{o}}$ ditolak yang menunjukkan bahwa Quality Of Work Life dan Beban Kerja secara simultan berpengaruh terhadap kepuasan kerja.

\section{Kesimpulan dan Saran}

\section{Kesimpulan}

1. Quality Of Work Life secara parsial tidak berpengaruh signifikan terhadap kepuasan kerja pegawai pada Kantor Kesyahbandaran dan Otoritas Pelabuhan Kelas II Kijang.

2. Beban Kerja secara parsial berpengaruh signifikan terhadap kepuasan kerja pegawai pada Kantor Kesyahbandaran dan Otoritas Pelabuhan Kelas II Kijang. Berdasarkan hasil pengujian yang dilakukan, beban kerja dipengaruhi langsung oleh kepuasan kerja

3. Quality Of Work Life dan Beban Kerja secara simultan berpengaruh signifikan terhadap kepuasan kerja pegawai pada Kantor Kesyahbandaran dan Otoritas Pelabuhan Kelas II Kijang.

\section{Saran}

1. Berdasarkan pembahasan variabel Quality Of Work Lifemenunjukkan bahwa adanya jenjang karir bagi pegawai karena akan meningkatkan keterampilan dari pegawai begitu juga indikator kompensasi rendah karena penggajian sudah berdasarkan golongan pegawai tersebut

2. Berdasarkan variabel beban kerja menunjukkan bahwa jumlah pegawai kurang memadai dan instansi tersebut dapat menambah jumlah pegawai agar penyelesaian pekerjaan dapat lebih efektif

3. Diperlukan bantual materil dan moral dari pihak pimpinan, agar para pegawai 
memberikan perhatian dan kepedulian terhadap pelaksanaan penelitian, sehingga proses penelitian dapat berjalan.

\section{Daftar Pustaka}

Alamsyah, Mohammad Indra. 2015. Pengaruh Motivasi dan Beban Kerja Terhadap Kepuasan Kerja Karyawan pada Dinas Perindustrian, Perdagangan, Koperasi, dan Usaha Kecil Menengah Daerah Istimewa Yogyakarta [Skripsi]. Yogyakarta: (ID). Universitas Negeri Yogyakarta.

Anditasari D. 2011. Analisis Faktor-Faktor Quality of Work Life Sebagai Pendukung Peningkatan Kinerja Karyawan ( Studi Kasus PT. Dafa Teknologi Mandiri, Ciampe Bogor) [Skripsi]. Bogor (ID): Institut Pertanian Bogor.

Arifin, Noor. 2012. Analisis Kualitas Kehidupan Kerja, Kinerja, dan Kepuasan Kerja pada CV Duta Senenan Jepara. Jepara: Volume 8, Nomor 1, April 2012.

Arika. 2011. Jurnal artikel Analisis Beban Kerja Ditinjau Dari Faktor Usia dengan Pendekatan Recommended Weight Limit

Astianto, Anggit., dan Suprihhadi Heru. 2014. Pengaruh Stres Kerja dan Beban Kerja Terhadap Kinerja Karyawan PDAM Surabaya. Surabaya: Vol 3 No. 7 (2014).

Augustine, Yvonne., Kristaung Robert. 2013. Metodologi Penelitian Bisnis dan Akuntansi. Jakarta: PT Dian Rakyat.

Badriyah, Mila. 2015. Manajemen Sumber daya Manusia.Cet. 1. Bandung: CV Pustaka Setia.

Dhamayanti A. 2007. Analisis kepuasan Karyawan Melalui Faktor- Faktor
Quality of Work Life di PT. Inti Abadi Kamasindo [Skripsi]. Bogor (ID): Institut Pertanian Bogor.

Dhani, rama dhini. 2010. Pengaruh stres kerja, beban kerja terhadap kepuasan kerja (Studi pada Medical Representatif di Kota Kudus.Vol.1. No.1.

Goetz, Katza.,dkk. 2013. The Influence Of Workload and Health Behavior On Job Satisfaction Of General Practitioner.Vol 45. No. 2. Feb 2013.

Handoko. 2011. Manajemen Personalia dan Sumber Daya Manusia. Edisi Revisi. Yogyakarta : BPFE

Hartatik. 2014. Buku Praktis Mengembangkan SDM. Cetakan Pertama. Jakarta : Laksana

Hasibuan MSP. 2003. Manajemen Sumber Daya Manusia. Edisi Revisi. Jakarta (ID): Bumi Aksara.

Hayati, Indah Kusuma. 2012. Analisis Penerapan Quality Of Work Life (QWL) Terhadap Kepuasan Kerja dan Komitmen Karyawan. Bogor: Semnas Fekon 2012: Optimisme Ekonomi Indonesia 2013, Antara Peluang dan Tantangan.

Irawati, S Anugrahini. 2015. Pengaruh Kualitas Khidupan Kerja Terhadap Kinerja Pegawai Dinas Perindustrian dan Perdagangan Kabupaten Sampang. Sampang: Volume 9, No, Des 2015.

Iskandar. 2008. Metodologi Penelitian Sistem Informasi. Yogyakarta : CV. ANDI OFFSET.

Jonathans, Cynthia Eveline. 2012. The Analysis Of Quality Of Work Life, Work Family Conflict And Job Stress On Job Satisfaction To Increase Employee Performence (Study In Jasa 
Raharja (Persero) Centraj Jaya. Jurnal Ekonomi manajemen. Semarang: Diponegoro University.

Khera, Aman. 2015. Impact of Quality of work life on job satisfaction: An Emprical Study on Nurses og Government Hospital in Chandigarh (india).The International Journal Of Business \& Management. Vol3 issue 8. August 2015.

Mahendrawan, I Gede., dan Indrawati, Ayu Desi. 2015. Pengaruh Beban Kerja dan Kompensasi Terhadap Kepuasan Kerja PT. Panca Dewata Denpasar. Denpasar: Vol. 4, No. 11, 2015: 3936-3961. ISSN: 2302-8912.

Mangkunegara AA. AP. 2001. Manajemen Sumber Daya Manusia Perusahaan. B a n d u n g ( I D ) : PT Remaja Rosdakarya. Nawawi H. 2006. Evaluasi dan Manajemen Kinerja di Lingkungan Perusahaan dan Industri. Yogyakarta (ID): Gajah Mada University Press.

Nurbi, Muhammad. 2013. Analisis pengaruh penerapan Quality of Work Life (QWL) Terhadap Kepuasan Kerja Karyawan (Studi Kasus PT Antam (Persero), Tbk UBPN Maluku Utara) [Skripsi]. Bogor (ID): Institut Pertanian Bogor.

Parmin. 2014. Pengaruh Kualitas Kehidupan Kerja, Disiplin Kerja dan Kompetensi terhadap Kinerja Pegawai pada PD. BPR BKK Kebumen. Kebumen: Volume 14.No 02, Des 2014.

Prasetyawati, Meri., dan Kusnudin. 2015. Pengaruh Quality Of Work Life Terhadap Kepuasan Kerja Karyawan di PT. Gemala Kempa Daya. Jakarta: Universita Muhammadiyah Jakarta. Volume 8 No. 1, Januari 2016.
Rokhman, Wahibur. 2013. Pengaruh Quality Of Work Life terhadap Kepuasan kerja, Komitmen Organisasi, Turover Intention dan Stres Kerja: Studi pada BMT di Kudus. Kudus: Volume 1, No 2, Desember 2013.

S Anugrahini Irawati.2015. Pengaruh Kualitas Kehidupan Kerja Terhadap Kinerja Pegawai Dinas Perindustrian dan Perdagangan kabupaten sampang. jurnal Neo-bis. Volume 9, No. 2, Des 2015.

Setiawan, Dani Praditya. 2016. Pengaruh Beban Kerja dan Lingkungan Kerja Terhadap Kinerja Karyawan PT. Macanan Jaya Cemerlang Klaten- JawaTengah-Indonesia.Yogyakarta:

Universitas Negeri Yogyakarta.

Sugiyono. 2005. Metode Penelitian Administrasi. Bandung : Alfabeta.

2010. Metode Penelitian Manajemen. Bandung : Alfabeta.

Sunyoto, Danang. 2011. Metodologi Penelitian Ekonomi. Cet 1 Yogyakarta: CAPS.

Surya Astitiani, Ni Luh Putu., dan Ketut Surya, Ida Bagus. 2016. Pengaruh Quality Of Work Life Terhadap Motivasi Kerja dan Kepuasan Kerja Karyawan.Bali: Universitas Udayana. Vol. 10. No. 2. Agustus 2016.

Purbaningrat Yo, Putu Melati., dan Ketut Surya, Ida Bagus. 2015. Pengaruh Beban Kerja Terhadap Kepuasan Kerja Dengan Stres Kerja Sebagai Variabel Mediasi. Bali: Vol. 4, No. 5, 2015 : 1149-1165. ISSN: 2302-8912. 